\title{
How Reading Books Fosters Language Development around the World
}

\author{
David K. Dickinson, ${ }^{1}$ Julie A. Griffith, ${ }^{1}$ Roberta Michnick Golinkoff, ${ }^{2}$ \\ and Kathy Hirsh-Pasek ${ }^{3}$ \\ ${ }^{1}$ Vanderbilt University, 230 Appleton Place, 230 Peabody, Nashville, TN 37203, USA \\ ${ }^{2}$ Departments of Psychology and Linguistics and Cognitive Science, University of Delaware, Newark, DE 19716, USA \\ ${ }^{3}$ Department of Psychology, Temple University, Philadelphia, PA 19003-2506, USA
}

Correspondence should be addressed to David K. Dickinson, david.dickinson@vanderbilt.edu

Received 23 August 2011; Accepted 20 November 2011

Academic Editor: Susan A. Gelman

Copyright (C) 2012 David K. Dickinson et al. This is an open access article distributed under the Creative Commons Attribution License, which permits unrestricted use, distribution, and reproduction in any medium, provided the original work is properly cited.

Research on literacy development is increasingly making clear the centrality of oral language to long-term literacy development, with longitudinal studies revealing the continuity between language ability in the preschool years and later reading. The language competencies that literacy builds upon begin to emerge as soon as children begin acquiring language; thus, the period between birth and age three also is important to later literacy. Book reading consistently has been found to have the power to create interactional contexts that nourish language development. Researchers, pediatricians, and librarians have taken notice of the potential for interventions designed to encourage parents to read with their children. This article reviews research on the connections between language and later reading, environmental factors associated with language learning, and interventions developed in varied countries for encouraging book use by parents of young children.

"The more that you read, the more things you will know. The more you learn, the more places you'll go." Dr. Seuss, "I Can Read With My Eyes Shut!"

\section{Introduction}

For roughly forty years, researchers interested in early reading and language development have studied the effects of early home and preschool experiences. Language has received particular attention because of its centrality to overall human development and its particular importance to reading development [1-3]. Dr. Seuss got it right in the quotation above: learning to read-and being read to-takes you to new places, both literally in terms of children's development and metaphorically as reading transports us to new vistas. As researchers examined differences between the growth trajectories of children from different backgrounds, it became apparent that environmental factors play a major role in determining the speed and ultimate success with which children learn to read [4]. Some children, notably those from homes where parents are poor and have limited educations, face particular challenges in learning to read $[5,6]$.

Developmental and cognitive psychologists probe the mysteries of language development and unravel the complexities of the reading process. Their findings have made increasingly apparent that particular kinds of experiences can play a special role in advancing language growth. The humble act of reading a book to a young child has repeatedly been found to have remarkable power [7]. Programs implemented in different countries that put books in the hands of parents and young children and that equip parents with effective strategies for using books consistently have been found to be effective methods of fostering language acquisition and improving children's early reading success.

In this paper, we first discuss research that demonstrates the profound and enduring connections between language 
development and later reading, then review research on language acquisition, arguing that later language learning builds on prior acquisition; thus, earlier acquisition propels later learning. We then discuss research on the effects of reading books with children between birth and age three and review research on the effectiveness of programs that supply books and dispense advice regarding their use to parents.

\section{Language and Reading}

2.1. Language and the Reading Process. Reading comprehension is critical for long-term academic success and is dependent on language abilities that emerge early in life. When all goes well, these early language experiences fuel effective reading comprehension among school-aged children and young adults. An illustration of the importance of language for reading would be reading a paragraph where many of the words were unknown to the reader although the reader could sound them out. Comprehension would be seriously impaired. The dependency of reading on oral language is at the core of the simple view of reading [2], a long-standing theory of reading development, and the more recent Convergent Skills Model of Reading (CSMR) [8], that builds on and slightly extends the simple view. Both theories seek to explain reading comprehension and draw on many of the same prior studies for support.

The CSMR hypothesizes that initially there is a primary dependence on code-based abilities such as linking sounds to letters and analyzing the sounds of spoken language into small units $[6,9,10]$. Increased attention to sounds along with knowledge of the names of letters facilitates the mapping of sound units onto graphemes [11]. Later, when initial decoding ability has been established, the semantic, syntactic, and pragmatic abilities that support language comprehension become of primary importance to successful reading comprehension [12]. The hypotheses of the CSMR were tested by assessing a large array of language- and reading-related skills among relatively early readers (grades 2 and $3, n=297$ ) and a group of older readers (grades 6 and $7, n=171$ ) who were from middle-income homes. As expected, code-related abilities played an important role at both ages, but contrary to expectations, semantic knowledge was an equal and powerful predictor at both ages. This finding and the results of work by other researchers $[13,14]$ make clear that semantic knowledge makes an important contribution to reading comprehension and that later reading failures often can be attributed to weakness in language ability [15].

New evidence from studies of twins points to environmental factors as primary determinants of emerging competencies related to language, reading, and schooling success. One study of 7,179 twins, roughly half of whom were identical and half fraternal, revealed that language development and reading ability are largely determined by environmental factors [16]. Another study of early vocabulary and expressive language found that environmental factors accounted for between $54 \%$ and $78 \%$ of the variation in language development [17]. Another study of a representative sample of twins born between April 1995 and December 1998 in the Greater Montreal area collected measures of parental reading when children were 19 months old and assessed school readiness at age 63 months [18]. This study and another analysis of the same data set [19] revealed that school readiness was primarily determined by environmental factors and that language plays an important role in predicting school readiness.

Important as vocabulary is, a singular focus on it risks reifying one element of a complex system and overlooks the contributions of the full language system [1]. Authors of a meta-analysis that reviewed work completed up until 2003 provided empirical support for this claim when they found that measures of "complex language," that is, language units beyond the single word, were better at predicting later reading than simple measures of vocabulary alone [10]. Another study found that age four language predicted grade two reading comprehension and that grammatical knowledge accounted for more variance than vocabulary [20].

Another strand of evidence highlights the subtle and pervasive effects of language on reading. For some time, it has been widely acknowledged that the ability to attend to the sounds of language is strongly associated with early reading success [21-23]. This ability is broadly described as "phonological awareness" with the most refined manifestation being "phonemic awareness," the ability to attend to discrete phonemes. The sources from which language awareness emerge are not fully understood. Intervention studies show that efforts to draw children's attention to the sounds of language can result in substantial growth in phonological awareness (e.g., $[10,24])$. But, there also is evidence for the effect of vocabulary learning on language awareness. When children learn many words with similar sounds, their ability to attend to the sounds of language is heightened. The process by which this occurs is referred to as lexical reorganization [25-27]. The effects of language learning on phonological awareness may well begin to be apparent in the years before children begin formal schooling as indicated by a study of 56 children who were followed from infancy into first grade [28]. Researchers found evidence of direct effects of early language ability on phonological awareness when children were beginning to learn to read and evidence of indirect effects of language, mediated by phonological awareness, on grade one decoding.

\section{The Organizing Role of Language between Birth and Age Five}

Parents know that between birth and school entry the growth of children's language abilities is astonishingly rapid. Less apparent are the profound effects that children's emerging language competencies have on their conceptual, interpersonal, and self-regulatory abilities. Dickinson et al. [29] have argued that literacy development, similar to other aspects of development, should be viewed from a system perspective $[30,31]$ and that language lies at the heart of this complex emerging constellation of competencies. A core tenet of systems theory is that the developmental point when processes are first being fashioned into a stable, 
interconnected network is when changes have the most enduring effects on the resulting system.

\subsection{Language Organizes and Interfaces with Multiple} Domains. The blossoming of language occurs at the same time that other conceptual and behavioral competencies are taking shape, providing the opportunity for language to influence and be influenced by multiple developmental domains. The far-reaching role of language in development has been stated by Tomasello [32]. Yet, Tomasello is also mindful that cognition and the ability to communicate are affected by social development and the child's ability to understand the perspectives of others. Nelson [31] makes this point even more forcefully. She reviewed extensive bodies of research on conceptual development, theory of mind, memory, and narrative and linked developmental shifts to the language abilities that become available during this era. She concluded that between the ages of two and six "...language and the surrounding culture take over the human mind. It is during these years that biology 'hands over' development to the social world" (page 325). Once children learn language, they also acquire a powerful tool to unite seemingly disparate instances of objects and events in the world (e.g., [33]; [34]). That is, the provision of a common label for a group of non identical objects or actions enables children to form a category of these instances, despite their variability.

Researchers who have studied social and emotional development, and who have an interest in the role of cognition in shaping social development [35], note the importance of language to children's emotion-related capabilities. Language, for example, seems to make it easier for children to regulate their own thoughts, feelings, and actions or abilities that are essential to social development and school success [36]. Preschool children with strong regulatory skills are better able to form positive relations with peers and teachers [37], display greater social competence in kindergarten [38], and have better achievement in kindergarten and beyond [39] relative to their peers with poorer regulatory skills. A precursor to self-regulation is the capacity for "effortful control" [40], an ability that begins to display consistently by age two [41]. Hints that this capacity may be linked to emerging language skill come from a study of twins [42] that found heritability effects on toddler's aggressive behaviors, but not on expressive vocabulary. Indeed, the acquisition of expressive vocabulary was related to less aggression. Similarly, in a study of preschool children, Kaiser found a relationship between behavior problems and low language [43]. Similarly, Hooper et al. [44] noted that expressive and receptive language deficits in kindergarten predicted later conduct problems. While these results are only correlational, they suggest that the ability to communicate to peers lessens the need to respond aggressively in a taxing situation. Thus, as Vygotsky long ago suggested [45], language is one tool that helps children learn to regulate their own emotions and behaviors and build relationships with others. Language ability also has far-reaching consequences for later social and academic functioning.

Next, we take this argument one step farther when we discuss the power of early parent-child book reading as a context for nourishing multiple aspects of development. Book reading provides an ideal setting for fostering language while at the same time building strong affective bonds between parents and children. Book reading also provides recurrent occasions for parents to help their infants and toddlers learn to regulate their attention and responses to stimuli. This is not because parents control these interactions "with an iron hand" but rather because children learn to naturally regulate their attention when they are focusing on a task they find interesting in a context that is nurturing, warm, and responsive. Children benefit when they and their parent establish a positive pattern of relating while reading, as revealed by a study in which 18 - to 22 -month-old children were observed while engaged in book reading [46]. Further, children with longer periods of joint attention at 18 months were found to have stronger productive vocabularies at 24 months. The relationship between language and vocabulary at two years of age and later language at school entry and beyond has also been documented by Marchman and Fernald [47].

\subsection{Early Language Learning Sets the Stage for Later Learning.} As language competencies emerge, they exert profound effects on conceptual, social, and affective functioning and build linguistic competencies that make subsequent language learning easier [48]. Language is a self-sustaining system that gathers momentum during the preschool years. There is evidence that language is an evolving self-reinforcing system even in the prelinguistic period. The language comprehension ability and the inclination of 14-month-old toddlers to use gestures to communicate predict their subsequent expressive and receptive vocabulary [49], suggesting that early encouragement to communicate may have beneficial effects. The use of child gestures at 14 months predicts their vocabulary at 54 months beyond the effects of socioeconomic status and even the amount of language children hear [50]. These data show that parents who honor their children's inchoate communicative attempts and use gesture themselves when communicating with their children have offspring who request more information and linguistic input through their own gestures. The insight that language builds on its own success has been formulated into a theory of the development of children's word learning abilities called the emergent coalitionist perspective [51-53]. Drawing on studies of word learning from infancy through the preschool years, this theory posits that children use multiple cues to learn words and that the cues employed to learn words change over developmental time. These changes occur because children become able to use language cues such as morphology and grammatical context and rely less on pointing and guesses about the intention of the other speaker. For example, if children hear "John snorked Mary," they can infer that "snorked" is likely a verb as it appears between two nouns and with a morphological end (/ed/) that is often found on verbs. This use of syntactic cues to help detect something of the meanings of words varies among children; those with weaker language skills have more difficulty employing syntactic cues to learn new words [54]. Further, as we noted previously, very young children's capacity to quickly process language 
is related to early vocabulary and language acquisition [55] and is predictive of vocabulary when children are eight years of age [47]. The impact of a preschooler's language ability on word learning also has been seen in studies in which children are taught new words by reading stories. Children with stronger language skills are more apt to learn more words than those with weaker skills unless special efforts are made to provide redundant and explicit information about word meanings $[56,57]$.

In the years between birth and age five early, language competencies facilitate the development of conceptual, affective, and attentional capacities. Language growth feeds upon itself and gains momentum during the preschool years. We now turn to consideration of how environmental factors influence the rate and course of language learning.

\section{Environmental Support for Language Learning}

There are various estimates of the size of children's vocabularies when they enter school, but a relatively conservative estimate is 5,000 base words $[58,59]$. If one assumes that children are not learning many words before the age of one and that school entry occurs at age five, then we can estimate that children learn roughly 3.5 words every day from age one to age five. Furthermore, they are acquiring mastery of the intricacies of their language's grammatical structure and learning to use language in socially appropriate ways.

Children, as opposed to the family's dog which also is surrounded by language, demonstrate such dramatic growth partly because there are biological adaptations that equip humans to understand and use language. However, this achievement does not occur in a vacuum; children must hear much language from adults willing to explain and expand, including a broad range of vocabulary and sentence structures, to show this growth. In other words, children need to engage in many language-based interactions with supportive adults. There are six principles that describe environmental factors that spur language learning, all of which can be activated as children hear books read aloud [60].

4.1. Principle 1: Children Need to Hear Many Words Often. Exposure to language plays an important role in children's emerging ability to interpret the meanings of words. Early language processing abilities are associated with the amount of language children hear [61-63], and by the second year of life, children's ability to rapidly understand words predicts their ability to comprehend language and learn new vocabulary [55]. Consider how this might work. If a child is slow at understanding language relative to her peers, she might be processing one part of a complex sentence while the speaker continues to talk. Eventually, a backlog might develop, and the child might lose some of what is being said. As Marchman and Fernald [47] concluded, the findings of their research "...suggest that processing speed and early language skills are fundamental to intellectual functioning" even predicting out to the child's 8th year of life (page 1).
Language input also varies dramatically as revealed by Hart and Risley's [64] study of children's home language environments between ages one and three. Less welleducated parents exposed children to far less language and a much smaller range of vocabulary than better-educated parents. Other correlational studies also have found variation in the amount of language exposure different children experience and association between exposure and rates of language acquisition [65-67]. Exposure to vocabulary is particularly likely to have beneficial effects when the input includes a relatively high density of novel words relative to total words [67-71]. Finally, recent research by Hackman and Farah [72] suggests that the language parts of the brain are affected by poverty more than other areas, resulting in differences related to brain structure at age five.

4.2. Principle 2: Children Learn Words When They Are Interested. Bloom [73] summarized research showing that language learning occurs best when talk is about objects or actions of immediate interest to children. One study demonstrated that children at 10 months of age systematically assume that a word label interesting, not boring objects [74]. It may well the case that many "mismappings" of this nature occur early on but are not revealed as most children do not yet talk. For children younger than about 18 months, studies of joint attention - that is, of times when adults and children attend to the same object or event-have found that adults who are more skilled in creating occasions of joint attention have children who have more advanced vocabularies [7577]. In fact, parents who try to redirect children's attention and label objects not of interest have children who learn fewer words $[53,76]$.

4.3. Principle 3: Children Learn Best When Adults Are Responsive to Them. Young children benefit from interacting with adults who offer prompt, contingent, and appropriate reactions to their utterances $[78,79]$, for example, parents who take turns, share periods of joint focus, and express positive affect $[77,80]$. One study found that when children were 9 and 13 months old maternal responsiveness was associated with how soon children reached different developmental milestones (e.g., put words together, talk about the past) [81]. Another study examined children at 6, 12, 24, and 40 months and found faster rates of cognitive development when mothers were sensitive to children's focus of attention and interests. Research by Hirsh-Pasek and Burchinal [82] affirms the relationship between sensitive and responsive adults and language and cognitive outcomes using the large longitudinal data set from the NICHD Study of Early Child Care. Both parents and caregivers who demonstrated stable responsive behavior across time from 6 to 54 months of age had children who were more cognitively competent. No doubt it is not only responsive language that controls these outcomes, but also the affective quality of motherchild interactions such that affective responsivity in early childhood projects out to cognitive competencies like mental ability scores at age 4, school readiness skills at age 5 and 6 , IQ scores at age 6 , and vocabulary and mathematics performance at age 12 [83]. 
Responsiveness of parents in terms of diversity of language also relates to later proficiency [84]. Further, the degree of responsiveness is especially important for children at medical risk due to low birth weight [85].

One question raised by this research concerns what exactly is meant by responsiveness. Children under the age of 3 do not seem to learn words when watching a televised show where there is little contingent responsive interaction $[86,87]$. They do learn the same words, however, in Skype conversations where the person communicates in a way that is directly responsive to the child [88]. Note principles 2 and 3 tease apart conversation in ways that focus on the interest and action of the child (Principle 2) and the role of the adult (Principle 3 ) in maintaining the conversation.

4.4. Principle 4: Words Are Learned When Meanings Are Made Clear. To increase their vocabulary, children need help understanding what they mean and how they are used. When young children converse with adults, they may be helped to grasp the meaning of words by, for example, having the adult directly tell them the word's meaning, pointing to an example of the word, or using intonation or gestures to signal the meaning. The children of parents who use such strategies have enhanced understanding of word meanings [84]. Direct teaching of word meanings has been found to speed acquisition in classrooms as well as in the home $[56,58,89]$. Word meanings also can be made apparent when a new word is used in the midst of on-going activity and when words are used to describe an object or concept that is connected to other concepts that are being discussed. For example, the word "ankle" is more likely to be learned as naming a part of the leg in the context of talk about toes, legs, or fingers than when used out of context (e.g., "My ankle hurts").

\subsection{Principle 5: Vocabulary and Grammar Are Learned} Together. While language includes distinct components (e.g., the lexicon, grammar, and phonological system) that can be studied and measured separately, children experience and learn language as an interconnected package. Therefore, it is not surprising that the amount and diversity of verbal stimulation children receive relates to growth of vocabulary and grammar $[64,70,90]$. Vocabulary and grammar are not divorced; rather, they feed one another. In a large sample of children aging 16-30 months $(n=1461)$, Dixon and Marchman [91] found that words and grammar developed in parallel. This relationship between grammar and vocabulary learning is also celebrated in research with bilingual children. Conboy and Thal [92] find, for example, that toddlers' English vocabulary predicted their English grammar and their Spanish vocabulary predicted their Spanish grammar.

Children learn vocabulary through grammar and grammar through vocabulary [93] in two ways. First, when children note the linguistic context in which words appear, they gain information about a word's part of speech [93]. Hearing, for example, "Where's my glorp?" tips children off to the fact that "glorp" must refer to a concrete object and likely be a noun. Indeed, as early as two and three years of age, respectively, children can use the sentence context in which novel nouns and verbs appear to identify the likely referents for these new terms in pictures $[94,95]$. Second, once a word is known, by observing the diverse linguistic contexts in which words are used, children detect nuances in word meaning [96]. Thus, "rigid" can refer to the properties of objects as well as characteristics of some people.

4.6. Principle 6: Keep It Positive. One of Hart and Risley's [64] startling finding was that lower-income children are far more likely to hear prohibitions (e.g., "Do not touch that!") than to hear what they called "affirmations" (e.g., "That's an interesting toy"). Prohibitions are not only more negative in tone, but they serve as conversation closers. In a lovely illustration, Chase-Lansdale and Takanishi [97] opened a recent report entitled, How do families matter?, with a vignette they called "three mothers and an eggplant."

\begin{abstract}
The first mother wheels her shopping cart down the produce aisle, where her kindergartner spots an eggplant and asks what it is. The mother shushes her child, ignoring the question. A second mother, faced with the same question, responds curtly, "Oh, that's an eggplant, but we do not eat it." The third mother coos, "Oh, that's an eggplant. It's one of the few purple vegetables." She picks it up, hands it to her son, and encourages him to put it on the scale. "Oh, look, it's about two pounds!" she says. "And it's $\$ 1.99$ a pound, so that would cost just about $\$ 4$. That's a bit pricey, but you like veal parmesan, and eggplant parmesan is delicious too. You'll love it. Let's buy one, take it home, cut it open. We'll make a dish together."
\end{abstract}

Rather than closing off the conversation, the third mother affirms the child's interest, speaks in full sentences, and continues the conversation in a way that builds vocabulary and grammar. When we expand on our children's language and ask questions rather than simply giving directives, we talk more and we create a climate that spurs language growth. Continuing the conversation increases the amount of talk, uses language in a social context, builds on children's interest, makes language meaningful, and generates more complex language samples.

Taken collectively, the six research-derived principles of language development offer a way to alter the trajectory of a child's language development. Teachers and parents can confidently give children a rich language base by applying the principles in areas that are of interest to them and their children. The trick is to start the conversation and keep it going as captured in the phrase Dickinson coined, "Strive for five," meaning five back and forth turns with the child. When conversations are only one-side prohibitions or one-word answers, children are not hearing the language they need to fuel their language-learning engine nor are they being sufficiently exposed to the concepts language encodes. In fact, a recent analysis by Chi [98] suggests that conversation requires children to engage in just the kind of interactive and constructive processing that fuels learning. 


\section{The Power of Book Reading in Instantiating the Six Principles of Language Learning}

Reading storybooks to children maximizes the kinds of experiences that predict language learning and may even exceed the power of oral conversations at times. There are at least three ways in which book reading influences language learning.

First, it offers children the opportunity to hear new vocabulary items embedded in varied grammatical sentences. Books written for children use well-formed, relatively short sentences that are rich in varied vocabulary. Furthermore, books often use the same words in diverse grammatical constructions, offering implicit lessons in how words are used. The texts of books tend to have more low-frequency words than does spoken language [99] and books encourage use of a wider range of words than would occur in everyday conversations. Indeed, Sénéchal and her colleagues (see, [100], for a review) consistently find that "parent reports of shared reading were a robust predictor of children's receptive and expressive vocabulary" (page 179).

The second way in which book reading enriches children's lives and language is that it promotes joint attention and interest. Consider all the ways in which storybooks conspire to help children maintain their attention. Children's books often use bold colors and strong contrasts and typically depict objects and animals that appeal to young children. The page of the book provides a clear focus for attention, and, unlike movable toys such as balls and trucks, books are held and remain relatively stationary. An attentive adult can easily notice what a child is attending to and build on it with commentary. In turn, children are able to draw an adult's attention to interesting pictures using a broad range of cues including gestures, sounds, and words. Thus, attention can be managed by the child as well as the adult.

Finally, book reading helps children learn language because it requires the participants to be active and engage in responsive interactions about word meanings. It is an opportunity for a parent or other caring adult to focus on the child and make efforts to be responsive to his or her interests. When parents and young children communicate around book reading and move away from the text as occurs during "dialogic reading" [101], they are engaging in a language-based activity that yields even more varied vocabulary and diverse sentences structures. Dialogic reading occurs when adults follow the child's interest and engage in conversation about material on the printed page or about experiences the child has had that relate to the story. Book reading becomes an "up close and personal" experience when done in this way and yields the most in the way of language learning $[10,101-103])$.

\section{Supporting Language Development between Birth and Age Three}

The evidence we have presented builds a strong case for the importance of making language a primary focus for early interventions. Language is affected by home patterns of communication, and it consistently lags among children from homes where parents are poor and have limited education. Between birth and age five, biological factors increase the beneficial and far-reaching effects of language input. Finally, there are well-researched approaches to supporting early language that can be delivered by parents at relatively low cost.

There is strong empirical support for using book reading as the core of an intervention. Since the 1990's, there have been several meta-analytic syntheses of experimental studies of reading interventions that have included work on children from the earliest years up through the beginning years of school. The criteria used to select studies differed in these reviews. Yet despite differences in the ages of the children included, and in the nature of the study (e.g., observational, experimental), all have concluded that book reading has moderate sized beneficial effects and that the impact of book reading is most evident in language ability [10, 104107]. Estimates of the size of the impact of book reading vary depending on the ages of the children, the type of intervention, and the outcome measures used, but what is constant is the finding that efforts to foster language that include books have positive and valuable effects. Based on results of two recent reviews $[10,107]$, it is safe to assume that a modest sized effect of 0.5 can be achieved for many such interventions, but effects may be greater for children with stronger vocabulary prior to the intervention [57] and children from higher SES families [107]. Analyses of studies that consider only children from birth to age three find evidence that these positive effects are magnified.

There have been relatively few studies of book reading among very young children (less than two years of age). The work that has been done indicates that interventions employing book reading can foster early language development especially in combination with tutorial support for parents in how to maximize the benefits of reading experiences. We now review programmatic efforts to use books to support development and then discuss specific features of book reading that are associated with enhanced development.

\section{Book Distribution Programs, Effectiveness, and Recommendations}

Recognition of the potential power of book reading to foster language and literacy has resulted in rapid spread of programs that distribute books to parents. Such programs have been implemented and evaluated in several countries. These interventions include some that have distributed books through local libraries and others that have used medical clinics. There is variability in the type of material distributed (books, literacy information, CDs, toys, etc.), in whether or not training was provided, and, if provided, in the content of the training (e.g., one-time literacy training, continuous training for physicians), in the country (United Kingdom, United States, Finland), in the population to whom the intervention was provided, and in the nature and amount of data collected. The research conducted on these programs has some methodological limitations that we discuss below, but the overall pattern of results is encouraging in that it points toward delivery mechanisms that have been found to work across countries. 
7.1. European Programs. The most impressive research on European book programs examined Bookstart, a program that has been widely implemented in the United Kingdom. Based in public libraries, it began in Birmingham with 300 inner city families. A major study examining its effects began when contact was made with mothers at 36 weeks of pregnancy. Families subsequently received four book packs over two years. A comparison group of infants who did not receive Bookstart packs was also followed through the course of the longitudinal study [108]. Data included initial questionnaires which were distributed six months after the first Bookstart pack was received, home activities surveys, observational studies conducted approximately two years after the first Bookstart pack was received, a baseline assessment upon start of school, and another assessment (SAT) at about age 7.5. Questionnaires revealed that most (71\%) parents bought more books for their children and $28 \%$ reported spending an increased amount of time sharing books with their children after receiving a Bookstart pack. The home activities surveys revealed that Bookstart children were significantly more likely than comparison group children to list looking at books as their favorite activity after receiving the Bookstart pack, and parents were significantly more likely to give their children books as presents after receiving the Bookstart pack. Observational studies in family homes found that Bookstart parents were significantly more likely than the comparison group to read the entire text of books, talk about the story, and encourage children to make predictions and connections-all precursors to later reading competence. Upon school entry, the baseline assessment that is administered to all children in the city by local authorities revealed that Bookstart children were ahead of a randomly selected control group $(n=41)$, especially in the categories of number and reading. Finally, the SAT assessment administered at age 7.5 (a national achievement test administered to all students in England at three points throughout their schooling) showed that Bookstart children were significantly ahead of the comparison group in all areas.

This study is noteworthy for the fact that it followed children from infancy into school, included observational data from homes as well as assessments, and had two comparison groups, one selected using random selection methods. Despite its strengths, one cannot draw strong causal conclusions because the initial sample was not selected using random methods, there is no information about how the books were used, and direct assessment of children did not occur until school entry, long after the intervention was over. It yields intriguing but far from conclusive evidence that the program had beneficial effects.

Two other studies have examined related book programs. In each case, they employ adult report measures to collect evidence of satisfaction with the program, but lack direct observational data or systematically identified control groups. The Cradle Club program was developed in conjunction with Bookstart and delivered as a morning session held for parents and their babies during which the librarians modeled play and reading for parents [108]. Librarians reported that the program was popular and believed it helped parents improve communication skills and encouraged them to share books with their children. Health professionals believed that it enabled them to engage in more conversations about literacy and that some families were encouraged to buy books as gifts instead of sweets. Nursery school teachers, who had a mixture of Bookstart children and non-Bookstart children, observed that the program had positive effects on the entire family and, in some cases, tried to implement similar programs for non-Bookstart children to make up for opportunities that may have been missed.

Also based in the United Kingdom, the Boots Books for Babies program distributed books and information through local health centers [109], and effects were studied both through questionnaires and an examination of library circulation records. A three-year program based on Bookstart, it was implemented from 1998-2000 and delivered book packs to caregivers at nine-month hearing checkups at local health centers. Health providers were given a short training at the beginning of the program through a partnership with a local college. The packets contained two children's books, an advertisement for the local library, copies of common nursery rhymes, a poster about community resources, and the link for a coordinating website. The links were also available in other languages when necessary. After two years, the impact of the Boots Books for Babies project was evaluated through parent questionnaires. Some parents said they used the library sooner than they might have before the program and the number of babies registered at local libraries rose by $54 \%$, an interesting outcome that could be the result of the project but lacking a control group design it is not possible to rule out other factors that could have been at work in the community at the time.

Babies Need Books, also in the UK, distributed books and information at health centers, baby clinics, parenting groups, and toddler groups [110]. Concurrently, the local libraries stocked a collection of books designed to appeal to these babies and their caregivers. This study also used library circulation as an outcome measure and found that $26 \%$ of babies in the Babies Need Books project were library users. Telephone interviews with parents revealed that shared book reading was an important part of most families' daily routines and parents mentioned the calming routine of book reading, the opportunity to spend special time together, and the opportunity to promote achievement through book reading. Parents also mentioned that grandparents started giving children books instead of sweets or toys for gifts after the intervention. Such changes in interactions between adults and children in homes is a potentially powerful byproduct of such programs that merits the use of direct observation or more careful tracking of home activities (e.g., regular phone calls to check on home activity) to guard against biases that occur when people report about their experiences.

Another library-based distribution program is Bookbabies, based in Finland [111]. The objective of this program is to encourage "having fun with books," a slogan chosen so as not to intimidate parents and one that is consistent with the self-reported effects of the Babies Need Books program. The target group for the study of this two-year intervention was 82 Flemish couples with young babies, with a special emphasis on hard-to-reach families. The project 
was based at local libraries, which also served as the hub for workshops and informational sessions for parents. In followup interviews, parents especially noted appreciation for the focus on enjoyment over performance when reading. They also reported that, after the Bookbabies program, they would be likely to introduce books to their children at a younger age than they would have before participating in the program.

7.2. Programs Based in the United States. In the United States, book distribution programs also have been developed and studied, but, in many cases, they also provide advice related to book use. Most of the evaluated programs for babies have used pediatricians to deliver the program, with Reach Out and Read being the premier program now implemented at over 4,000 sites in the United States and abroad [112]. The appeal of this approach is that all children have access to to health clinics, and they serve low-income children [112, 113]. During the first five years of life, most children are seen 1315 times, allowing for guidance and support from a trusted health care provider. The cost of such book distribution programs is much lower than intervention programs such as home visits or Head Start [112]. In Reach Out and Read, the waiting room of the doctor's office is utilized to train parents in reading techniques as volunteers read books to children who are waiting, and pediatricians incorporate questions about reading to children into their health visit [113]. Additionally, a free, developmentally and culturally appropriate book is distributed to families at each visit. The focus is on teaching children to love to read and not on learning to read early.

Evaluations of the Reach Out and Read program have found positive effects, with parent report data being used but several studies using comparison group designs and testing data (reviewed in [113]). Key findings include mothers listing book reading as their favorite activity after the intervention, parental reports of more frequent reading, and, importantly, evidence that Reach Out and Read children score higher in receptive and expressive language than non-Reach Out and Read children $[113,114]$. Also, there is evidence that families that receive more intervention show more effects, a fact that lends further weight to the argument that the program has a causal impact on children and parents [114].

Two large-scale efforts in the United States based in public libraries have sought to train parents to engage children in conversations around books rather that reading straight through books. This work has sought to encourage the use of a method known as dialogic reading [101]. In the first such endeavor, children's librarians were taught to introduce dialogic reading to parents of 28-month-old children either in one-hour sessions in the library or by viewing a training video [115]. This large randomized trial project included 588 children and had clear positive effects. Analysis of videotapes of reading sessions revealed a four-fold increase in the use of dialogic methods by the experimental group. Importantly, children's observed mean length of utterance and amount of talk during the reading event increased significantly. The authors noted that parents who had not received the training did not naturally use the recommended methods, suggesting that there may be value in providing guidance to all parents. At a three-month followup, researchers found continued use of the methods, and parents reported a reduction in parenting stress. The inperson training was found to be more effective than videobased training. But parents who only received the video training outperformed the control group, indicating that even if a program cannot deliver training in person, training that is delivered using technology (e.g., videotape, internet) may still have beneficial effects.

A subsequent study examined the comparative value of video based as opposed to live training using the same basic research design [116]. Some parents received live training, some were sent videotapes with a follow-up phone conversations about the method, and others used the videotapes on their own. Beneficial effects were observed on children's expressive language for all approaches, with the impact being similar across intervention methods except for parents with limited educational background. Those with only high school level education needed the live training in order to benefit from the method.

\section{Dimensions of Book Reading Associated with Enhanced Development}

While simply creating opportunities for parents and caregivers to read to children has predictable beneficial effects, research has identified a number of dimensions of book reading that are associated with greater effects. Knowledge of these can be of value to those planning and supporting book-reading interventions.

8.1. Frequency and Age of Onset of Book Reading. The most fundamental issue relating to the impact of reading on children is reading frequency. One of the first meta-analyses of book reading [104] drove this point home by noting that frequency of reading was more important than social economic class in predicting children's growth.

The importance of reading frequency for children from birth to age three was clearly revealed by findings of a large study of low-income mothers, $39 \%$ of whom were teenagers when their child was born [117]. Mothers' reports of daily book reading at age 14 months related to vocabulary and language comprehension at 14 and 24 months. When discussing results of path analyses, the authors stated, "...the period from 14 to 24 months appears to be one during which child language and maternal book reading may together begin a "snowball" effect for subsequent book reading experiences and development" (page 944). An additional demonstration of the long-term impact of early book reading comes from a study of twins that sought to parcel out environmental from genetic effects on school readiness. Researchers [18] tracked children from 6 to 63 months and found that SES was strongly related to school readiness, but that its effects were mediated in two ways: SES affected the frequency of book reading, and book reading was directly related to school readiness. SES-related effects on expressive language were through its impact on the frequency of book reading.

There is also evidence that the age at which parents begin to read to children is important. One observational 
study found that children in households where reading was reported with children as young as eight months had stronger early language growth [118]. An intervention study conducted with middle class families compared the effects of interactive reading when their babies were 4 months old and when babies were 8 months old. Only the condition with older babies was effective, with improved language abilities being found when the babies were 12 and 16 months old [119].

8.2. Book Reading Style: Observational Studies. Variation in how books are read and discussed has been found to be important. Ninio [120] examined interactions between Israeli mothers and babies who were between 17- and 22months old and included 20 middle class and 20 lower class mothers. Mothers tended to use one of three interactional routines, asking one of two types of questions "What's that?," "Where's that?," or simply naming objects. Mothers from all backgrounds were most likely to ask the more verbally advanced children to name things ("what's that?"), but middle class mothers were more likely to label objects for the least advanced children and to request pointing responses from children with stronger language skills. Less educated mothers talked less and used fewer names for actions and features of objects, and the rate of their children's language development was slower. A similar study compared the reading styles of working class Caucasian and African-American mothers in the United States with similar education levels [121]. There were many similarities in how books were used, but AfricanAmerican mothers used significantly fewer questioning behaviors, and Caucasian children produced comments in response to maternal questions whereas African-American children produced more spontaneous comments.

A large study of the reading approaches of 126 teenage mothers found stylistic variability in how they read to their children at age 7 and 24 months [122]. Maternal style was related to language growth, with children faring better when they were encouraged to participate in the reading and supported in their understanding, but this style was found in only 30 of 126 mothers and was concentrated among the most verbal mothers.

Many experimental studies have sought to encourage parents to adopt ways of reading and discussing books found to be related to enhanced learning. By far the most common method adopted is dialogic reading. As described earlier, dialogic reading was found to have beneficial effects on a variety of measures of productive language when used by middle class mothers of two years old children [101]. The model quickly became popular and has been used in many studies with preschool and kindergarten aged children. The upward shift in age is important to note because the most recently published meta-analysis of dialogic reading found that it loses its value with the older children [105]. It may be that the method is best suited to book reading with infants, toddlers, and younger preschool children.

This method has been extended to 2-year-old children in a community day care center in Mexico [103]. Over a period of 6 to 7 weeks, the researcher engaged children, selected because they had the lowest language skills, with resulting strong positive effects on standardized measures of language. The authors of this paper concluded,

The implementation of this intervention in a regular Mexican day care center is relevant to the potential application of early intervention programs in underdeveloped countries. These countries lack the economic resources to conduct thorough, intensive intervention programs such as Head Start. Small-scale intervention programs such as the present study demonstrated that within the poor conditions in operation at this day care center, the dialogicreading program had an impact on children's linguistic development. ...We expect that continuous exposure to picture book activities would produce larger and more lasting effects... (page 113).

8.3. Attachment and Responsiveness. Language acquisition occurs in the context of intimate interactions between adults and children. Woven into these interactions are periods of joint attention when adult and child attend to the same object or event. Ideally, there is a complex and sensitive tuning of warm, supportive parental actions, and language in response to children's language and behavior. Such dynamics give rise to strong affective bonds between mothers and children that also foster language growth [82]. Book reading is one setting in which parents' abilities to engage in such interactions can be observed.

Researchers interested in mother-child attachment have found that the quality of attachment is related to how children engage in book reading, with more securely attached children more likely to be able to establish and maintain joint attention with their mothers and with fewer disruptions caused by the need for discipline [123]. Given the importance of attachment for children's overall development, interventions have been designed with the goal of enhancing the quality of parenting. The most well-developed such method is playing and learning strategies (PALSs), a program for coaching maternal responsiveness $[124,125]$. PALS seeks to help mothers to consistently give prompt, sensitive responses to children's actions, to express positive affect, to help the child manage attention, and to provide language input. Children of mothers who participated were more communicative and cooperative [124]. Mothers who participated during infancy displayed increased expressions of warmth and skill in helping children maintain their focus of attention, but improvement in children's vocabulary and complex language skills occurred only when parents received support once their child was old enough to actively use language [125].

A similar approach has been developed for use in the offices of pediatricians [126]. In the Video Interaction Project (VIP), when mothers visit the pediatrician for their child's regular checkup, they also receive help in learning to be responsive when interacting with their infants and toddlers. In one study, 150 dyads were assigned to either VIP or control groups, and analysis of book reading events found significant effects on children for mothers with at least a 7 th 
grade education (see, [126]). Research continues to explore the impact of VIP, with evidence that it results in improved sensitivity in parenting, lessens disruptive behaviors, and enhances cognitive and language development [127].

8.4. Summary. Studies of book reading have found evidence that children begin to benefit when regular reading begins as early as 8 months and that children benefit most from regular reading routines that include sensitive and responsive, language-rich interactional routines. Evidence from multiple countries suggests that the simple act of providing books to families can increase the frequency of reading, of library use and may have beneficial effects on interactions around books. By and large studies of distribution programs have been relatively small in scale and lacking in resources to conduct rigorous research. Data sometimes is not collected prior to or at the beginning of the intervention, random assignment to condition is very rare, and parent reports often are the primary form of data. This type of research may well provide feedback to programs that is of value, but additional rigor is needed if strong conclusions are to be drawn.

\section{Implications for Nonwestern and Developing Nations}

Research on book reading has been concentrated in the United States, Europe, and Israel so it is difficult to know the extent to which findings can generalize to developing nations. One study conducted in Chile examined reading practices among 188 families from different SES backgrounds [128]. They found low rates of early literacy knowledge and found that $42 \%$ of the families had fewer than 10 books in the home. Books that were owned tended to come from farmer's markets, super markets, and street vendors rather than bookstores. This pattern of acquisition suggests that these books are often of poor quality and that many may be simply coloring books or books of stickers. Families in Chile may have limited access to places that sell high quality children's literature, and similar issues of availability likely exist in many other developing countries. Indeed, issues of access may become increasingly common even in communities in economically advantaged areas as the number of bookstores dwindles under pressures from electronic distribution systems. Internet-based purchases of books are on the rise. In the future, differential access to the internet and associated access to credit could translate into differential access to books, further disadvantaging the poorest families.

Across studies conducted with different populations, there is the consistent finding that the educational level of parents affects reading, with more well-educated parents typically adopting more supportive methods. As is the case in the United States, there are also likely differences in approaches to book reading among ethnic groups. Support for this point comes from the Netherlands where interactions of Surinamese-Dutch mothers were compared with those of Turkish-Dutch and Dutch mothers. Differences in the amount of talk were associated with literacy level, but ethnic differences that may have been associated with beliefs about child rearing also affected how mothers read [129].
Caution is advised, however, before presuming that SES differences are always the key variable in book reading interactions. Chilean middle and lower SES mothers of 12to 24-month-old infants were observed interacting with their children [130]. Mothers of both groups adjusted their styles to match the abilities of their children, indicating that all parents were sensitive to their children's language level and able to tune their own behavior accordingly. In addition, the Huebner and Meltzoff [116] study conducted in the United States with parents from different backgrounds found that dialogic reading methods were not spontaneously used by parents [116]. Thus, any intervention should assume that all parents may find some of the methods being recommended to be novel.

Although group-level differences are prevalent, there are also family-specific differences in what is called the "scholarly orientation" of families. A recent analysis of a huge database of interview data from over 70,000 cases drawn from 27 countries representing the full spectrum of political philosophy (e.g., communist, Western style democratic) has examined the impact of book ownership on the social mobility of families [131]. This unique study started from the premise that families vary in their orientation toward the importance of education and operationalized this construct using people's recollections of the number of books they had in their home when growing up. After controlling for income, education, time in history, and country of origin, the authors found that the number of books owned led to substantial increases in the years children attended school. The impact of book ownership is greatest among families with the least education and the fewest books. Across all countries, they found that, among families with no formal education, the impact of owning 25 books instead of none, was two additional years of schooling. If they owned 500 books this translated into two more years of schooling. In parents with primary grade schooling ( 8.8 years), owning 25 instead of no books also added about two years of schooling. These are correlations; therefore, one cannot presume that putting 25 more books in homes will result in such changes in schooling. What the data do indicate is that families whose value structures are such that they have acquired books, kept them, and passed them down from one generation to the next value schooling and learning. Although simply giving books may not create a scholarly orientation in families, interventions can help parents and babies experience the pleasures of reading and instill a love of reading and books that might nourish attitudes that lead to placing a higher value on education.

\section{Future Research}

Much of the research that has been done has examined the effects of a small set of approaches, many of which may not be feasible to employ in developing countries or in poorly resourced communities in Western countries. Research is needed to understand alternative ways of delivering books and guidance in their use and into examination of how these services are and are not taken up by families. Data on the impact of interventions on attitudes and reported 
practices is useful and inexpensive to collect but is subject to bias on the part of respondents. Much remains to be learned about specific ways that family practices are affected by interventions and the extent to which such changes have enduring effects.

Book programs often spring from community sources, and research tends to be done with a limited budget and, as a result, lacks elements found in rigorous scientific research. In many developing countries, research funding is quite limited, but effort should be made to conduct at least small-scale studies before scarce resources are spent on programs that may be well meaning but of limited value. Critical issues worthy of such investigation include the following.

(1) The functioning of the program needs to be studied from the perspective of those being served. Can and do they access the service? Can they receive the material regularly enough to benefit? Are they motivated to participate? Can they understand the training? Are the things to be read in a language they can read and understand?

(2) The delivery of the program needs to be examined. How are the services and material delivered? Is the required level of expertise for delivering the service available? What are motivations for the entity delivering the service to provide it and does it maintain the quality required for success. In other words, the fidelity with which the program is delivered should be studied.

(3) What are anticipated effects of the intervention and how will they be described? A pilot study should be used to ensure that the approaches being considered will be feasible given the resources and the context.

Research that is done should be conducted in as rigorous a manner as possible given the context. Projects should consider the following strategies that can help address methodological flaws that are present in some of the following prior studies.

(1) Track some who do not receive the service. If random assignment is not possible try to identify those who are as similar as possible to those receiving services. Collect the same data from these subjects as is collected from the sample receiving the services.

(2) Collect data prior to or very early in the project so as to have stronger evidence of possible changes in practices.

(3) Collect information about the processes that are critical to the study, including the quality of delivery of the service or training (e.g., whether books were received, if appropriate advice was given), and the extent to which training guidance was followed. Limit asking for recollection of long-past events. Use phone calls, surveys, or other data collection that asks about recent activities (e.g., that day, the past week or month). Such data might be collected on selected cases if it is not possible to do so for the full sample.
(4) Strive to get objective data about children and, if relevant, adult-child interactions. Observations of book reading and direct assessment of children yield the strongest data.

(5) Seek to use indirect measures of impact using data sources such as library circulation records or testing data carried out by school systems to provide a way to compare your data to larger samples or to get other forms of objective data about your sample.

\section{Conclusion}

Research on child development has established beyond doubt the fact that the years between birth and age three are critical for children's long-term language, cognitive, emotional, and interpersonal development. To an extent, the power of these years springs from the fact that the brain is maturing rapidly and is sensitive to environmental stimulation or lack thereof. Also, this is the time when linguistic, cognitive, affective, and regulatory systems are developing and becoming interdependent. At this critical juncture, book reading has special power to have enduring impact on parents' patterns of interpersonal interaction with their children in a way that has lasting consequences for them. As parents read with children, they have the opportunity for frequent, sensitively tuned, language-rich interactions that draw children into conversations about books, the world, language and concepts. However, most parents do not spontaneously make the most of the opportunities that books present and many lack access to high quality books. Multiple programs from several countries have demonstrated that these twin challenges can be met. Large-scale distribution of high quality books and useful information is possible when coordinated through existing respected community agencies, especially if parents are responsive to and benefit from advice regarding how to best engage their child. Further, when the distribution of books is accompanied by guidance in how to read those books, there is enormous potential to enhance reading and self-regulatory competencies. There is evidence that simply providing books has value, especially in settings where very few books are otherwise available, but evidence is much stronger that the combination of books and guidance for reading has great potential to result in and lead to more frequent and more effective reading and improvements in children's language and self-regulatory competencies.

\section{Disclosure}

An earlier version of this was written for the Instituto Alpha E Beto, Rio de Janeiro, Brazil for translation into Portuguese and distribution in Brazil.

\section{References}

[1] D. K. Dickinson, A. McCabe, L. Anastasopoulos, E. S. Peisner-Feinberg, and M. D. Poe, "The comprehensive language approach to early literacy: the interrelationships among vocabulary, phonological sensitivity, and print 
knowledge among preschool-aged children," Journal of Educational Psychology, vol. 95, no. 3, pp. 465-481, 2003.

[2] W. A. Hoover and P. B. Gough, "The simple view of reading," Reading and Writing, vol. 2, no. 2, pp. 127-160, 1990.

[3] F. R. Vellutino, W. E. Tunmer, J. J. Jaccard, and R. Chen, "Components of reading ability: multivariate evidence for a convergent skills model of reading development," Scientific Studies of Reading, vol. 11, no. 1, pp. 3-32, 2007.

[4] J. Harris, R. M. Golinkoff, and K. Hirsh-Pasek, "Lessons from the crib for the classroom: how children really learn vocabulary," in Handbook of Early Literacy Research, S. B. Neuman and D. K. Dickinson, Eds., vol. 3, pp. 49-65, Guildford, New York, 2011.

[5] C. E. Snow, M. S. Burns, and P. Griffin, Eds., Preventing Reading Difficulties in Young Children, National Research Council, National Academy Press, Washington, DC, USA, 1998.

[6] G. J. Whitehurst and C. J. Lonigan, "Child development and emergent literacy," Child Development, vol. 69, no. 3, pp. 848872, 1998.

[7] E. T. Rodriguez, C. S. Tamis-LeMonda, M. E. Spellmann et al., "The formative role of home literacy experiences across the first three years of life in children from low-income families," Journal of Applied Developmental Psychology, vol. 30, no. 6, pp. 677-694, 2009.

[8] F. R. Vellutino, W. E. Tunmer, J. J. Jaccard, and R. Chen, "Components of reading ability: multivariate evidence for a convergent skills model of reading development," Scientific Studies of Reading, vol. 11, no. 1, pp. 3-32, 2007.

[9] C. J. Lonigan, S. R. Burgess, and J. L. Anthony, "Development of emergent literacy and early reading skills in preschool children: evidence from a latent-variable longitudinal study," Developmental Psychology, vol. 36, no. 5, pp. 596-613, 2000.

[10] National Early Literacy Panel, Developing early literacy: Report of the national early literacy panel, National Institute for Literacy, Jessup, Md, USA, 2009.

[11] L. C. Ehri, S. R. Nunes, D. M. Willows, B. V. Schuster, Z. Yaghoub-Zadeh, and T. Shanahan, "Phonemic awareness instruction helps children learn to read: evidence from the National Reading Panels meta-analysis," Reading Research Quarterly, vol. 36, no. 3, pp. 250-283, 2001.

[12] D. K. Dickinson, R. M. Golinkoff, and K. Hirsh-Pasek, "Speaking out for language: why language is central to reading development," Educational Researcher, vol. 39, no. 4, pp. 305-310, 2010.

[13] H. W. Catts, S. M. Adlof, and S. E. Weismer, "Language deficits in poor comprehenders: a case for the simple view of reading," Journal of Speech, Language, and Hearing Research, vol. 49, no. 2, pp. 278-293, 2006.

[14] K. Nation, P. Clarke, C. M. Marshall, and M. Durand, "Hidden language impairments in children: parallels between poor reading comprehension and specific language impairment?" Journal of Speech, Language, and Hearing Research, vol. 47, no. 1, pp. 199-211, 2004.

[15] J. Ricketts, K. Nation, and D. V. M. Bishop, "Vocabulary is important for some, but not all reading skills," Scientific Studies of Reading, vol. 11, no. 3, pp. 235-257, 2007.

[16] N. Harlaar, M. E. Hayiou-Thomas, P. S. Dale, and Robert Plomin, "Why do preschool language abilities correlate with later reading? A twin study," Journal of Speech, Language, and Hearing Research, vol. 51, no. 3, pp. 688-705, 2008.

[17] C. A. Van Hulle, H. H. Goldsmith, and K. S. Lemery, "Genetic, environmental, and gender effects on individual differences in toddler expressive language," Journal of Speech,
Language, and Hearing Research, vol. 47, no. 4, pp. 904-912, 2004.

[18] N. Forget-Dubois, G. Dionne, J. P. Lemelin, D. Pérusse, R. E. Tremblay, and M. Boivin, "Early child language mediates the relation between home environment and school readiness," Child Development, vol. 80, no. 3, pp. 736-749, 2009.

[19] J. P. Lemelin, M. Boivin, N. Forget-Dubois et al., "The genetic-environmental etiology of cognitive school readiness and later academic achievement in early childhood," Child Development, vol. 78, no. 6, pp. 1855-1869, 2007.

[20] V. Muter, C. Hulme, M. J. Snowling, and J. Stevenson, "Phonemes, rimes, vocabulary, and grammatical skills as foundations of early reading development: evidence from a longitudinal study," Developmental Psychology, vol. 40, no. 5, pp. 665-681, 2004.

[21] K. E. Stanovich, "Matthew effects in reading: some consequences of individual differences in the acquisition of literacy," Reading Research Quarterly, vol. 21, pp. 360-407, 1986.

[22] R. K. Wagner and J. K. Torgesen, "The nature of phonological processing and its causal role in the acquisition of reading skills," Psychological Bulletin, vol. 101, no. 2, pp. 192-212, 1987.

[23] J. K. Torgesen, R. K. Wagner, C. A. Rashotte, S. R. Burgess, and S. A. Hecht, "Contributions of phonological awareness and rapid automatic naming ability to the growth of wordreading skills in second-to-fifth grade children," Scientific Studies of Reading, vol. 1, pp. 161-185, 1997.

[24] National Reading Panel, Report of the National Reading Panel: Teaching Children to Read Reports of the Subgroups, National Institute for Literacy, 2000.

[25] J. L. Metsala and A. C. Walley, "Spoken vocabulary growth and the segmental restructuring of lexical representations: precursors to phonological awareness and early reading ability," in Education and Cognitive Development: A Natural Experiment, J. L. Morrison, F. J. Smith, and M. DowEhrensberger, Eds., vol. 31, pp. 789-799, Lawrence Erlbaum, Mehwah, NJ, USA, 1998.

[26] J. L. Metsala, "Young children's phonological awareness and nonword repetition as a function of vocabulary development," Journal of Educational Psychology, vol. 91, no. 1, pp. 3-19, 1999.

[27] J. Metsala, "Lexical reorganization and the emergence of phonological awareness," in Handbook of Early Literacy Research, S. B. Neuman and D. K. Dickinson, Eds., vol. 3, Guilford, New York, NY, USA, 2011.

[28] M. Silvén, E. Poskiparta, P. Niemi, and M. Voeten, "Precursors of reading skill from infancy to first grade in finnish: continuity and change in a highly inflected language," Journal of Educational Psychology, vol. 99, no. 3, pp. 516-531, 2007.

[29] D. K. Dickinson, A. McCabe, and M. A. Essex, "A window of opportunity we must open to all: the case for high-quality support for language and literacy," in Handbook of Early Literacy Research, D. K. Dickinson and S. B. Neuman, Eds., vol. 2, pp. 11-28, Guilford, New York, NY, USA, 2006.

[30] D. H. Ford and R. M. Lerner, Developmental Systems Theory: An Integrative Approach, Sage, Newbury Park, Calif, USA, 1992.

[31] K. Nelson, Language in Cognitive Development: The Emergence of the Mediated Mind, Cambridge University Press, New York, NY, USA, 1996.

[32] M. Tomasello, The Cultural Origins of Human Cognition, Harvard University Press, Cambridge, Mass, USA, 1999. 
[33] L. Song, A. Stahl, S. Ranganathan, R. M. Golinkoff, and K. Hirsh-Pasek, "Labeling facilitates 19- to 21- month-olds' categorization of intransitive human actions," in Society for Research in Child Development Conference, Montreal, Canada, April 2011.

[34] S. R. Waxman and S. A. Gelman, "Different kinds of concepts and different kinds of words: what words do for human cognition," in The Making of Human Concepts, D. Mareschal, P. C. Quinn, and S. E. G. Lea, Eds., Oxford University Press, Oxford, UK, 2010.

[35] C. Saarni, The Development of Emotional Competence, Guilford, New York, NY, USA, 1999.

[36] C. Blair, "School readiness: integrating cognition and emotion in a neurobiological conceptualization of children's functioning at school entry," American Psychologist, vol. 57, no. 2, pp. 111-127, 2002.

[37] A. L. Miller, K. K. Gouley, R. Seifer, S. Dickstein, and A. Shields, "Emotions and behaviors in the head start classroom: associations among observed dysregulation, social competence, and preschool adjustment," Early Education and Development, vol. 15, no. 2, pp. 147-165, 2004.

[38] S. A. Denham, K. A. Blair, E. Demulder et al., "Preschool emotional competence: pathways to social competence," Child Development, vol. 74, no. 1, pp. 238-256, 2003.

[39] R. B. Howse, S. D. Calkins, A. D. Anastopoulos, S. P. Keane, and T. L. Shelton, "Regulatory contributions to children's kindergarten achievement," Early Education and Development, vol. 14, pp. 101-119, 2003.

[40] M. K. Rothbart, L. K. Ellis, M. R. Rueda, and M. I. Posner, "Developing mechanisms of temperamental effortful control," Journal of Personality, vol. 71, no. 6, pp. 1113-1143, 2003.

[41] G. Kochanska, K. C. Coy, and K. T. Murray, "The development of self-regulation in the first four years of life," Child Development, vol. 72, no. 4, pp. 1091-1111, 2001.

[42] G. Dionne, R. Tremblay, M. Boivin, D. Laplante, and D. Pérusse, "Physical aggression and expressive vocabulary in 19-month-old twins," Developmental Psychology, vol. 39, no. 2, pp. 261-273, 2003.

[43] A. P. Kaiser, M. Y. Roberts, and R. H. McCleod, "Young children with language impairments: challenges in transition to reading," in Handbook of early literacy research, S. B. Neuman and D. K. Dickinson, Eds., vol. 3, Guilford, New York, NY, USA, 2011.

[44] S. R. Hooper, J. E. Roberts, S. A. Zeisel, and M. Poe, "Core language predictors of behavioral functioning in early elementary school children: concurrent and longitudinal findings," Behavioral Disorders, vol. 29, no. 1, pp. 10-24, 2003.

[45] L. Vygotsky, Thought and Language, MIT Press, Cambridge, Mass, USA, 1986.

[46] K. L. Fletcher, A. Perez, C. Hooper, and A. H. Claussen, "Responsiveness and attention during picture-book reading in 18-month-old to 24-month-old toddlers at risk," Early Child Development and Care, vol. 175, no. 1, pp. 63-83, 2005.

[47] V. A. Marchman and A. Fernald, "Speed of word recognition and vocabulary knowledge in infancy predict cognitive and language outcomes in later childhood: Fast-Track Report," Developmental Science, vol. 11, no. 3, pp. F9-F16, 2008.

[48] L. B. Smith, "How domain general processes create domainspecific biases," in Conceptual Development and Language Acquisition, M. Bowerman and S. Levinson, Eds., Cambridge University Press, Cambridge, UK, 2000.
[49] N. Watt, A. Wetherby, and S. Shumway, "Prelinguistic predictors of language outcome at 3 years of age," Journal of Speech, Language, and Hearing Research, vol. 49, no. 6, pp. 1224-1237, 2006.

[50] M. L. Rowe, Ş. Özçalişkan, and S. Goldin-Meadow, "Learning words by hand: Gesture's role in predicting vocabulary development," First Language, vol. 28, no. 2, pp. 182-199, 2008.

[51] R. M. Golinkoff and K. Hirsh-Pasek, "Baby wordsmith from associationist to social sophisticate," Current Directions in Psychological Science, vol. 15, no. 1, pp. 30-33, 2006.

[52] K. Hirsh-Pasek, R. Golinkoff, E. A. Hennon, and M. J. Maguire, "Hybrid theories at the frontier of developmental psychology: the emergenist coalition of word learning as a case in point," in Weaving a Lexicon, D. G. Hall and S. R. Waxman, Eds., pp. 173-204, MIT Press, Cambridge, Mass, USA, 2004.

[53] G. J. Hollich, K. Hirsh-Pasek, R. M. Golinkoff et al., "Breaking the language barrier: an Emergentist coalition model of the origins of word learning," Monographs of the Society for Research in Child Development, vol. 65, no. 3, pp. $\mathrm{x} 1-122,2000$.

[54] N. Kemp, E. Lieven, and M. Tomasello, "Young children's knowledge of the "determiner" and "adjective" categories," Journal of Speech, Language, and Hearing Research, vol. 48, no. 3, pp. 592-609, 2005.

[55] A. Fernald, A. Perfors, and V. A. Marchman, "Picking up speed in understanding: speech processing efficiency and vocabulary growth across the 2nd year," Developmental Psychology, vol. 42, no. 1, pp. 98-116, 2006.

[56] W. B. Elley, "Vocabulary acquisition from listening to stories," Reading Research Quarterly, vol. 24, pp. 174-187, 1989.

[57] J. F. Penno, I. A. G. Wilkinson, and D. W. Moore, "Vocabulary acquisition from teacher explanation and repeated listening to stories: do they overcome the Matthew effect?" Journal of Educational Psychology, vol. 94, no. 1, pp. 23-33, 2002.

[58] A. Biemiller, "Vocabulary development and instruction: a prerequisite for school learning," in Handbook of Early Literacy Research, D. K. Dickinson and S. B. Neuman, Eds., vol. 2, pp. 41-51, Guilford, New York, NY, USA, 2006.

[59] A. Biemiller and N. Slonim, "Estimating root word vocabulary growth in normative and advantaged populations: evidence for a common sequence of vocabulary acquisition," Journal of Educational Psychology, vol. 93, no. 3, pp. 498-520, 2001.

[60] D. K. Dickinson, K. Hirsh-Pasek, and R. Golinkoff, Increasing Vocabulary in Preschoolers: Using Cognitive Science to Guide Pedagogy, Vanderbilt University, Nashville, Tenn, USA, 2010.

[61] A. Fernald and A. Weisleder, "Early language experience is vital to developing fluency in understanding," in Handbook of Early Literacy Research, S. B. Neuman and D. K. Dickinson, Eds., vol. 3, Guilford, New York, NY, USA, 2011.

[62] N. Hurtado, V. A. Marchman, and A. Fernald, "Spoken word recognition by Latino children learning Spanish as their first language," Journal of Child Language, vol. 34, no. 2, pp. 227249, 2007.

[63] N. Hurtado, V. A. Marchman, and A. Fernald, "Does input influence uptake? Links between maternal talk, processing speed and vocabulary size in Spanish-learning children," Developmental Science, vol. 11, no. 6, pp. F31-F39, 2008.

[64] B. Hart and T. Risley, Meaningful Differences in the Everyday Lives of American Children, Brookes Publishing, Baltimore, Md, USA, 1995. 
[65] E. Hoff, "How social contexts support and shape language development," Developmental Review, vol. 26, no. 1, pp. 55$88,2006$.

[66] E. Hoff-Ginsberg, "Mother-child conversation in different social classes and communicative settings," Child development, vol. 62, no. 4, pp. 782-796, 1991.

[67] E. Hoff and L. Naigles, "How children use input to acquire a lexicon," Child Development, vol. 73, no. 2, pp. 418-433, 2002.

[68] D. K. Dickinson, T. R. Flushman, and J. B. Freiberg, "Language, reading and classroom supports: Where we are and where we need to be going," in Vocabulary Studies in First and Second Language Acquisition: The Interface between Theory and Application, B. Richards, M. H. Daller, D. Malvern et al., Eds., pp. 396-429, Palgrave-MacMillan, Hampshire, UK, 2009.

[69] E. Hoff, "The specificity of environmental influence: socieconomic status affects early vocabulary development via maternal speech," Child Development, vol. 74, no. 5, pp. 1368-1378, 2003.

[70] J. Huttenlocher, W. Haight, A. Bryk, M. Seltzer, and T. Lyons, "Early vocabulary growth: relation to language input and gender," Developmental Psychology, vol. 27, no. 2, pp. 236248, 1991.

[71] B. A. Pan, M. L. Rowe, J. D. Singer, and C. E. Snow, "Maternal correlates of growth in toddler vocabulary production in lowincome families," Child Development, vol. 76, no. 4, pp. $763-$ 782, 2005.

[72] D. A. Hackman and M. J. Farah, "Socioeconomic status and the developing brain," Trends in Cognitive Sciences, vol. 13, no. 2, pp. 65-73, 2009.

[73] P. Bloom, How Children Learn the Meanings of Words, MIT Press, Cambridge, Mass, USA, 2000.

[74] S. M. Pruden, K. Hirsh-Pasek, R. M. Golinkoff, and E. A. Hennon, "The birth of words: ten-month-olds learn words through perceptual salience," Child Development, vol. 77, no. 2, pp. 266-280, 2006.

[75] N. Akhtar, F. Dunham, and P. J. Dunham, "Directive interactions and early vocabulary development: the role of joint attentional focus," Journal of Child Language, vol. 18, no. 1, pp. 41-49, 1991.

[76] P. J. Dunham, F. Dunham, and A. Curwin, "Joint-attentional states and lexical acquisition at 18 months," Developmental Psychology, vol. 29, no. 5, pp. 827-831, 1993.

[77] M. Tomasello and M. J. Farrar, "Joint attention and early language," Child development, vol. 57, no. 6, pp. 1454-1463, 1986.

[78] C. Tamis-LeMonda, T. Cristofaro, E. Rodriguez, and M. Bornstein, "Early language development:Social influences in the first year of life," in Child Psychology: A Handbook of Contemporary Issues, L. Balter and C. Tamis-LeMonda, Eds., Psychology Press, New York, NY, USA, 2006.

[79] M. H. Bornstein, C. S. Tamis-LeMonda, C. S. Hahn, and O. M. Haynes, "Maternal responsiveness to young children at three ages: a longitudinal analysis of a multidimensional, modular and specific parenting construct," Developmental Psychology, vol. 44, no. 3, pp. 867-874, 2008.

[80] C. Howes, "Social-emotional classroom climate in child care, child-teacher relationships and children's second grade peer relations," Social Development, vol. 9, no. 2, pp. 191-204, 2000.

[81] C. S. Tamis-LeMonda, M. H. Bornstein, and L. Baumwell, "Maternal responsiveness and children's achievement of language milestones," Child Development, vol. 72, no. 3, pp. 748-767, 2001.

[82] K. Hirsh-Pasek and M. Burchinal, "Putting language learning in context: how change at home and in school affects language growth across time," Merrill Palmer Quarterly, vol. 52, pp. 449-485, 2006.

[83] P. Estrada, W. F. Arsenio, R. D. Hess, and S. D. Holloway, "Affective quality of the mother-child relationship: longitudinal consequences for children's school-relevant cognitive functioning," Developmental Psychology, vol. 23, no. 2, pp. 210-215, 1987.

[84] Z. O. Weizman and C. E. Snow, "Lexical input as related to children's vocabulary acquisition: effects of sophisticated exposure and support for meaning," Developmental Psychology, vol. 37, no. 2, pp. 265-279, 2001.

[85] S. H. Landry, K. E. Smith, C. L. Miller-Loncar, and P. R. Swank, "Predicting cognitive-language and social growth curves from early maternal behaviors in children at varying degrees of biological risk," Developmental psychology, vol. 33, no. 6, pp. 1040-1053, 1997.

[86] G. A. Strouse, Dialogic video: influence of dialogic reading techniques on preschoolers' learning from video stories, Ph.D. thesis, Psychology, Vanderbilt, Nashville, Tenn, USA, 2011.

[87] S. Roseberry, K. Hirsh-Pasek, J. Parish-Morris, and R. M. Golinkoff, "Live action: can young children learn verbs from video?” Child Development, vol. 80, no. 5, pp. 1360-1375, 2009.

[88] S. Roseberry, Blicking through video chats: The role of contingency in toddlers' ability to learn novel verbs, Doctoral dissertation, Temple University, 2010.

[89] A. Biemiller and C. Boote, "An effective method for building meaning vocabulary in primary grades," Journal of Educational Psychology, vol. 98, no. 1, pp. 44-62, 2006.

[90] C. E. Snow, W. S. Barnes, J. Chandler, I. F. Goodman, and L. Hemphill, Unfulfilled Expectations: Home and School Influences on Literacy, Harvard, Cambridge, Mass, USA, 1991.

[91] J. A. Dixon and V. A. Marchman, "Grammar and the lexicon: developmental ordering in language acquisition," Child Development, vol. 78, no. 1, pp. 190-212, 2007.

[92] B. T. Conboy and D. J. Thal, "Ties between the lexicon and grammar: cross-sectional and longitudinal studies of bilingual toddlers," Child Development, vol. 77, no. 3, pp. 712-735, 2006.

[93] M. Imai, L. Li, E. Haryu et al., "Novel noun and verb learning in Chinese-, English-, and Japanese-speaking children," Child Development, vol. 79, no. 4, pp. 979-1000, 2008.

[94] R. M. Golinkoff, K. Hirsh-Pasek, L. M. Bailey, and N. R. Wenger, "Young children and adults use lexical principles to learn new nouns," Developmental Psychology, vol. 28, no. 1, pp. 99-108, 1992.

[95] R. M. Golinkoff, R. C. Jacquet, K. Hirsh-Pasek, and R. Nandakumar, "Lexical principles may underlie the learning of verbs," Child Development, vol. 67, no. 6, pp. 3101-3119, 1996.

[96] J. Gillette, H. Gleitman, L. Gleitman, and A. Lederer, "Human simulations of vocabulary learning," Cognition, vol. 73, no. 2, pp. 135-176, 1999.

[97] P. L. Chase-Lansdale and E. Takanishi, "How do families matter? Understanding how families strengthen their children's educational achievement," Report from the Foundation for child development, New York, NY, USA, October, 2009.

[98] M. T. H. Chi, "Active-constructive-interactive: a conceptual framework for differentiating learning activities," Topics in Cognitive Science, vol. 1, no. 1, pp. 73-105, 2009. 
[99] D. K. Dickinson and P. O. Tabors, Eds., Beginning Literacy with Language: Young Children Learning at Home and School, Brookes Publishing, Baltimore, Md, USA, 2001.

[100] M. Sénéchal, "A model of the concurrent and longitudinal relations between home literacy and child outcomes," in Handbook of Early Literacy Research, S. B. Neuman and D. K. Dickinson, Eds., vol. 3, pp. 175-188, Guilford, New York, NY, USA, 2011.

[101] G. J. Whitehurst, F. L. Falco, C. J. Lonigan et al., "Accelerating language development through picture book reading," Developmental Psychology, vol. 24, no. 4, pp. 552-559, 1988.

[102] D. H. Arnold, C. J. Lonigan, G. J. Whitehurst, and J. N. Epstein, "Accelerating language development through picture book reading: replication and extension to a videotape training format," Journal of Educational Psychology, vol. 86, no. 2, pp. 235-243, 1994.

[103] M. C. Valdez-Menchaca and G. J. Whitehurst, "Accelerating language development through picture book reading: a systematic extension to mexican day care," Developmental Psychology, vol. 28, no. 6, pp. 1106-1114, 1992.

[104] A. G. Bus, M. H. van Ijzendoorn, and A. D. Pellegrini, "Joint book reading makes for success in learning to read: a meta-analysis on intergenerational transmission of literacy," Review of Educational Research, vol. 65, no. 1, pp. 1-21, 1995.

[105] S. E. Mol, A. G. Bus, M. T. De Jong, and D. J. H. Smeets, "Added value of dialogic parent-child book readings: a metaanalysis," Early Education and Development, vol. 19, no. 1, pp. 7-26, 2008.

[106] H. S. Scarborough and W. Dobrich, "On the efficacy of reading to preschoolers," Developmental Review, vol. 14, no. 3, pp. 245-302, 1994.

[107] L. M. Marulis and S. B. Neuman, "The effects of vocabulary intervention on young children's word learning: a metaanalysis," Review of Educational Research, vol. 80, no. 3, pp. 300-335, 2010.

[108] M. Moore and B. Wade, "Bookstart: a qualitative evaluation," Educational Review, vol. 55, no. 1, pp. 3-13, 2003.

[109] M. Bailey, C. Harrison, and G. Brooks, "The boots books for babies project: impact on library registrations and book loans," Journal of Early Childhood Literacy, vol. 2, no. 1, pp. 45-63, 2002.

[110] E. Hall, "Babies, books and 'impact': problems and possibilities in the evaluation of a Bookstart project," Educational Review, vol. 53, no. 1, pp. 57-64, 2001.

[111] B. Vanobbergen, M. Daems, and S. Van Tilburg, "Bookbabies, their parents and the library: an evaluation of a Flemish reading programme in families with young children," Educational Review, vol. 61, no. 3, pp. 277-287, 2009.

[112] A. L. Mendelsohn, B. P. Dreyer et al., "Fostering early development and school readiness in pediatric settings," in Handbook of Early Literacy Research, S. B. Neuman and D. K. Dickinson, Eds., vol. 3, pp. 279-294, Guildford, New York, NY, USA, 2011.

[113] R. Needlman, P. Klass et al., "A pediatric approahc to early literacy," in Handbook of Early Literacy Research, D. K. Dickinson and S. B. Neuman, Eds., vol. 2, pp. 333-346, Guilford, New York, NY, USA, 2006.

[114] B. Zuckerman, "Promoting early literacy in pediatric practice: twenty years of reach out and read," Pediatrics, vol. 124, no. 6, pp. 1660-1665, 2009.

[115] C. E. Huebner, "Promoting toddlers' language development through community-based intervention," Journal of Applied Developmental Psychology, vol. 21, no. 5, pp. 513-535, 2000.
[116] C. E. Huebner and A. N. Meltzoff, "Intervention to change parent-child reading style: a comparison of instructional methods," Journal of Applied Developmental Psychology, vol. 26, no. 3, pp. 296-313, 2005.

[117] H. Raikes, G. Luze, J. Brooks-Gunn et al., "Mother-child bookreading in low-income families: correlates and outcomes during the first three years of life," Child Development, vol. 77, no. 4, pp. 924-953, 2006.

[118] B. D. Debaryshe, "Joint picture-book reading correlates of early oral language skill," Journal of Child Language, vol. 20, no. 2, pp. 455-461, 1993.

[119] J. Karrass and J. M. Braungart-Rieker, "Effects of shared parent-infant book reading on early language acquisition," Journal of Applied Developmental Psychology, vol. 26, no. 2, pp. 133-148, 2005.

[120] A. Ninio, "Picture-book reading in mother-infant dyads belonging to two subgroups in Israel," Child Development, vol. 51, no. 2, pp. 587-590, 1980.

[121] J. Anderson-Yockel and W. O. Haynes, "Joint book-reading strategies in working-class African American and white mother-toddler dyads," Journal of Speech and Hearing Research, vol. 37, no. 3, pp. 583-593, 1994.

[122] P. R. Britto, J. Brooks-Gunn, and T. M. Griffin, "Maternal reading and teaching patterns: associations with school readiness in low-income African American families," Reading Research Quarterly, vol. 41, no. 1, pp. 68-89, 2006.

[123] A. G. Bus and M. H. Vanijzendoorn, "Mothers reading to their 3-year-olds - the role of mother-child attachment security in becoming literate," Reading Research Quarterly, vol. 30, no. 4, pp. 998-1015, 1995.

[124] S. H. Landry, K. E. Smith, and P. R. Swank, "Responsive parenting: establishing early foundations for social, communication, and independent problem-solving skills," Developmental Psychology, vol. 42, no. 4, pp. 627-642, 2006.

[125] S. H. Landry, K. E. Smith, P. R. Swank, and C. Guttentag, "A responsive parenting intervention: the optimal timing across early childhood for impacting maternal behaviors and child outcomes," Developmental Psychology, vol. 44, no. 5, pp. 1335-1353, 2008.

[126] A. L. Mendelsohn, L. N. Mogilner, B. P. Dreyer et al., "The impact of a clinic-based literacy intervention on language development in inner-city preschool children," Pediatrics, vol. 107, no. 1, pp. 130-134, 2001.

[127] A. L. Mendelsohn, B. P. Dreyer, C. A. Brockmeyer, S. B. Berkule-Silberman, and L. M. Morrow, "Fostering early development and school readiness in pediatric settings," in Handbook of Early Literacy Research, S. B. Neuman and D. K. Dickinson, Eds., vol. 3, Guildford, New York, NY, USA, 2010.

[128] K. Strasser and M. R. Lissi, "Home and instruction effects on emergent literacy in a sample of chilean kindergarten children," Scientific Studies of Reading, vol. 13, no. 2, pp. 175204, 2009.

[129] A. G. Bus, P. P. M. Leseman, and P. Keultjes, "Joint book reading across cultures: a comparison of Surinamese-Dutch, Turkish-Dutch, and Dutch parent-child dyads," Journal of Literacy Research, vol. 32, no. 1, pp. 53-76, 2000.

[130] O. A. P. de Mendoza, "Developmental changes and socioeconomic differences in mother-infant picturebook reading," European Journal of Psychology of Education, vol. 10, no. 3, pp. 261-272, 1995.

[131] M. D. R. Evans, J. Kelley, J. Sikora, and D. J. Treiman, "Family scholarly culture and educational success: books and schooling in 27 nations," Research in Social Stratification and Mobility, vol. 28, no. 2, pp. 171-197, 2010. 


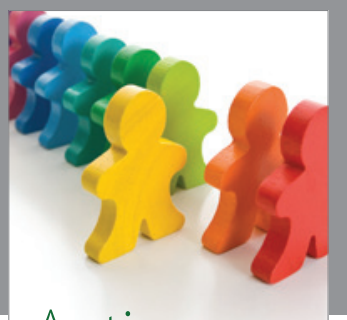

Autism

Research and Treatment
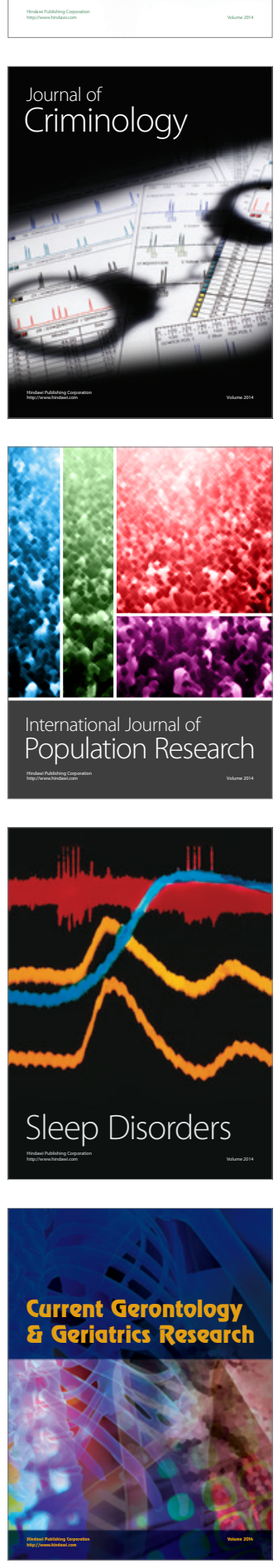
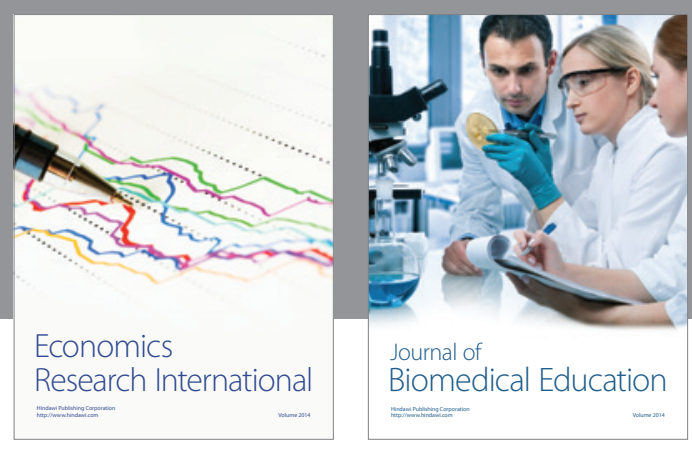

Journal of

Biomedical Education

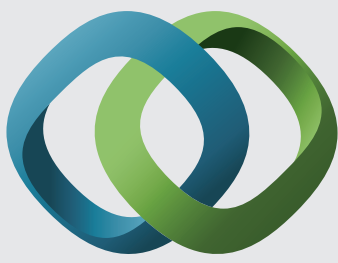

\section{Hindawi}

Submit your manuscripts at

http://www.hindawi.com
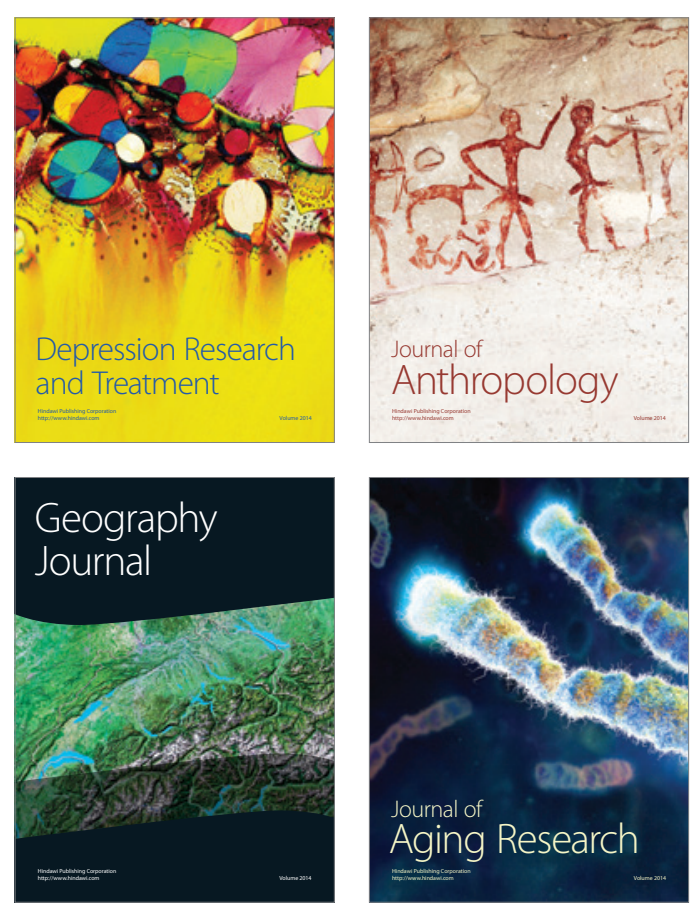

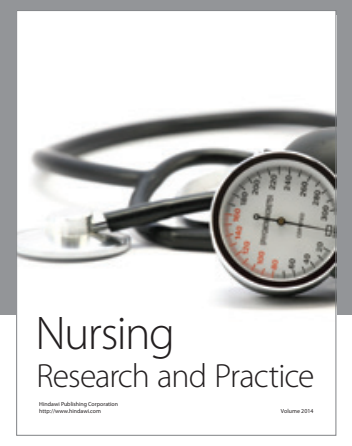

Nursing

Research and Practice

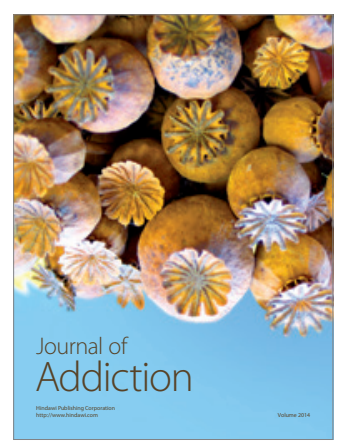

Child Development

Research

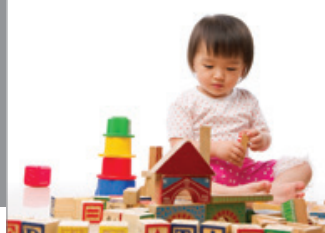

迥
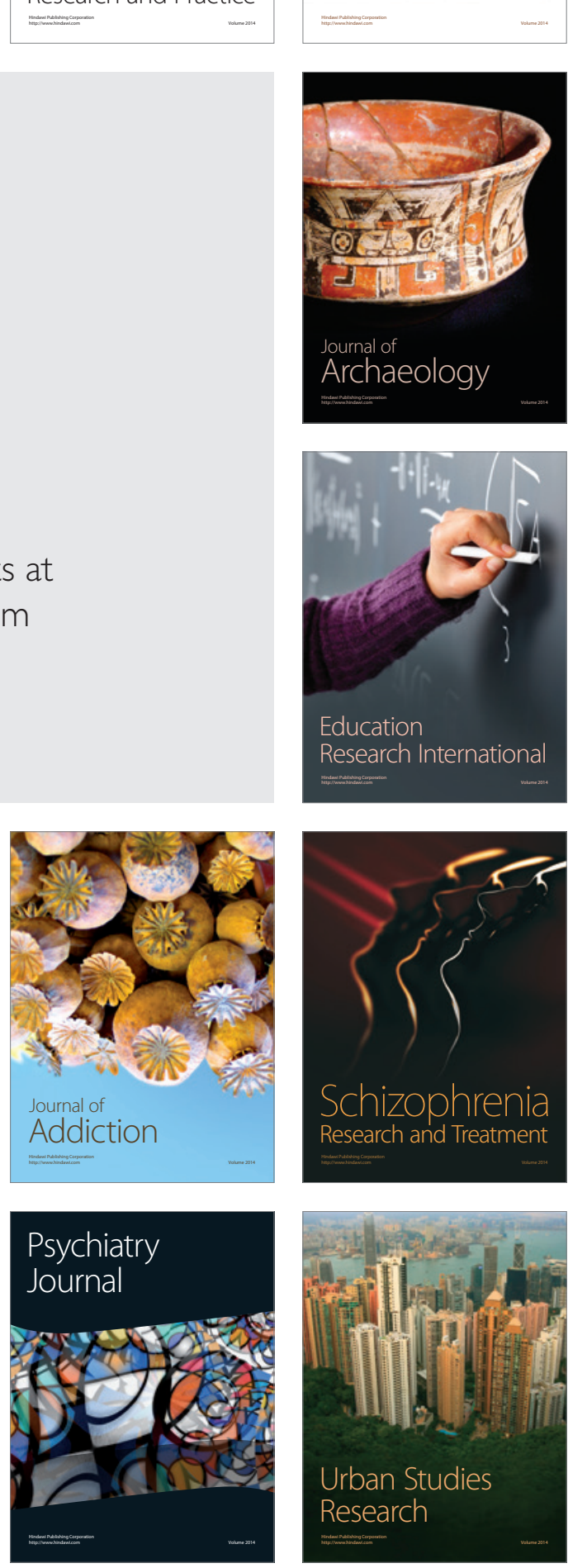